\title{
Treatment of Traumatic Acetabulum Lesions in an African Orthopaedic Trauma Department
}

\author{
S. C. Da, S. A. Korsaga, Aji Ouedraogo, C. Darga, H. Kafando, M. O. Somé, S. Tinto, D. Denné, \\ L. Ouédraogo, M. Sawadogo
}

Department of Orthopedics-Traumatology, University Hospital Yalgado Ouedraogo, Ouagadougou, Burkina Faso

Email: songahirda@yahoo.fr

How to cite this paper: Da, S.C., Korsaga, S.A., Ouedraogo, A., Darga, C., Kafando, H., Somé, M.O., Tinto, S., Denné, D., Ouédraogo, L. and Sawadogo, M. (2019) Treatment of Traumatic Acetabulum Lesions in an African Orthopaedic Trauma Department. Open Journal of Orthopedics, 9, 197-211.

https://doi.org/10.4236/ojo.2019.910021

Received: August 27, 2019

Accepted: October 12, 2019

Published: October 15, 2019

Copyright $\odot 2019$ by author(s) and Scientific Research Publishing Inc. This work is licensed under the Creative Commons Attribution International License (CC BY 4.0).

http://creativecommons.org/licenses/by/4.0/

\begin{abstract}
Background: The management of traumatic acetabular injuries (TAI), which are often complex and diverse, is difficult and costly in the context of lowincome African countries. Objective: To evaluate the treatment of traumatic acetabular lesions in the Orthopedics and Traumatology Department of the Yalgado Ouedraogo University Hospital, for their better management. Patients and Methods: This was a retrospective study, conducted in our department from January 2012 to December 2016. Sixty-three patients with TAI and complete records were selected. The mean age of patients with coxofemoral dislocations was 34.2 years and 36.4 years for acetabulum fractures with male predominance in both injury types. The injuries were mainly caused by a violent road traffic accident (RTA) (90.5\%). Forty hip dislocations and 41 acetabular fractures were reported, with a prevalence of iliac dislocations $(52.5 \%)$ and posterior wall fractures of the acetabulum (24.4\%). Results: The average time to manage TAI was 15.9 hours (range 2 - 100). Medical treatment was performed in all patients. Thirty-eight coxofemoral dislocations and 34 acetabular fractures were treated by orthopedic methods. Seven complex acetabular fractures and two coxo-femoral dislocations were performed by surgical method. Two patients died (3.2\%), one in a hemorrhagic shock table and the other in a septic shock table. Immediate and late complications were identified. Conclusion: Early and adequate management of our TAI, requires a modern technical platform and a sufficient number of qualified medical personnel to improve their functional outcomes.
\end{abstract}

\section{Keywords}

Hip, Acetabulum, Dislocation, Fracture, Treatment

\section{Introduction}

The management of traumatic, complex and diverse acetabulum injuries is often 
difficult and costly in the context of low-income African countries. These traumatic lesions mainly consist of rare fractures of the acetabulum and coxo-femoral dislocations. They are often caused by a high energy trauma, involving the functional prognosis of the affected hip or even the vital prognosis of the injured person. Coxo-femoral traumatic dislocation, an absolute traumatological emergency [1], is characterized by a permanent displacement of the femoral head out of the acetabular cavity; they are consecutive to capsulo-ligamentous lesions, on a hip in a favorable position [1] [2]. Acetabulum fractures are often complex and unstable, affecting hip function by development of hip osteoarthritis [3] [4]. At the instigation of Judet [5] and on the basis of 1000 operated cases [4], these fractures were classified into singles and complexes [1], according to a radiological classification [4] [6] [7]. They are often part of a context of polytrauma. In general, they do not require urgent treatment [8]; hence the possibility of postponing their reduction to treat other more urgent lesions. It is in this context that we want, by this study, to bring our experience of the treatment of TAI to the Orthopedics-Traumatology department of the University Hospital Center of Yalgado Ouedraogo, in order to identify the appropriate measures of their best care.

\section{Patients and Methods}

This was a descriptive and analytical study with retrospective collection of medical records of patients with TAI between January 1, 2012 and December 31, 2016.

\subsection{Inclusion Criteria}

Patients with traumatic dislocation and/or fracture of the acetabulum and aged at least 15 years, admitted to the Orthopedic-Traumatology Department of the Yalgado Ouedraogo Teaching Hospital, and having a complete clinical file, were selected.

\subsection{Criteria of Non-Registration}

Excluded from our study:

- Patients whose files were incomplete and therefore unusable;

- Patients who have not been followed and treated in our service;

- Patients who have been discharged against medical advice before being treated;

- Patients with non-traumatic conditions of acetabulum.

We performed an exhaustive collection of patient data from medical records, open rum registers, trauma emergency registers, surgeon's consultation records and medical certificates. The data was collected on an individual file, entered on a microcomputer and analyzed with Epi Info ${ }^{\mathrm{TM}}$ Version 7.2.1.0 statistical analysis and statistics software in its French version. The graphics were made with the Microsoft Office Excel 2010 softwares.

The socio-demographic variables (age, origin, sex, occupation), etiological variables (circumstances, mechanisms and type of collision) and the consultation period were collated. 
The anatomo-clinical variables (affected side, functional signs, physical signs, anatomical type of dislocation, type of acetabular fracture, lesion association) were identified.

Radiological variables (conventional radiography: face, profile and $3 / 4$, computed tomography, magnetic resonance imaging) were collected.

Therapeutic variables (time to treatment, reduction methods, post-reduction contentions, post-reduction outcomes and complications, post-treatment outcomes) were collected and the anonymity of the patients and the confidentiality of the medical information were collected. We have adopted the rating of Postel Merle d'Aubigné which takes into account both subjective and objective criteria (pain, walking and mobility) to evaluate our functional results; each parameter is rated from 0 to 6 (Table 1). So were qualified:

- Excellent results, the hips listed 18;

- Very good results, hips rated 17;

- good results, the hips listed 16 - 15;

- Passable results, the hips listed 14 - 13;

- Poor results, the hips are 12 - 11 - 10;

- Bad results a rating lower than 9.

Post-treatment X-rays allowed us to evaluate the reduction of displacements according to the criteria of Matta et al. [10]:

- Anatomical reduction: $1 \mathrm{~mm}$ maximum displacement at the fracture focus on the 3 bearings (face, $3 / 4$ wing, $3 / 4$ shutter).

- Satisfactory reduction: $3 \mathrm{~mm}$ maximum displacement on one of the 3 bearings.

Table 1. Functional evaluation criteria according to the Postel Merle d'Aubigné [10].

\begin{tabular}{|c|c|c|c|}
\hline Cote & Pain & Mobility & Walking \\
\hline 0 & $\begin{array}{l}\text { Very severe and } \\
\text { continuous pain }\end{array}$ & $\begin{array}{l}\text { Ankylosis in a } \\
\text { vicious attitude }\end{array}$ & Impossible walking \\
\hline 1 & $\begin{array}{l}\text { Very severe pain } \\
\text { preventing sleep }\end{array}$ & $\begin{array}{l}\text { Clinical hookworm } \\
\text { with vicious attitude } \\
\text { slight or none }\end{array}$ & Only with crutches \\
\hline 2 & $\begin{array}{l}\text { Severe pain in the walking and } \\
\text { preventing any bending activity }\end{array}$ & $\begin{array}{l}\text { Flexion: } 40^{\circ} \\
\text { Abduction: } 00^{\circ}\end{array}$ & Only with two sticks \\
\hline 3 & $\begin{array}{l}\text { Severe pain but tolerable } \\
\text { with limited activities }\end{array}$ & Flexion: $40^{\circ}$ à $60^{\circ}$ & $\begin{array}{c}\text { Limited with a cane } \\
\text { (less than one hour) } \\
\text { Very difficult } \\
\text { without cane }\end{array}$ \\
\hline 4 & $\begin{array}{l}\text { Pain only after walking } \\
\text { disappearing after resting }\end{array}$ & Flexion: $80^{\circ}$ à $90^{\circ}$ & $\begin{array}{l}\text { With a cane, even } \\
\text { extended. Limited } \\
\text { without cane } \\
\text { (claudication) }\end{array}$ \\
\hline 5 & $\begin{array}{l}\text { Very mild and intermittent pain that } \\
\text { does not prevent normal activity }\end{array}$ & $\begin{array}{l}\text { Flexion: } 80^{\circ} \text { à } 90^{\circ} \\
\text { Abduction: } 25^{\circ}\end{array}$ & $\begin{array}{l}\text { Without cane but } \\
\text { slight claudication }\end{array}$ \\
\hline 6 & Complete indolence & $\begin{array}{l}\text { Flexion: } 90^{\circ} \\
\text { Abduction: } 40^{\circ}\end{array}$ & Normal \\
\hline
\end{tabular}


- Unsatisfactory reduction: more than $3 \mathrm{~mm}$ of movement on at least one of the 3 incidences.

The congruence between the femoral head and the roof of the acetabulum, and between the femoral head and the entire acetabulum, was evaluated according to the criteria of Duquennoy et al. [10]. This head/roof congruity "TT" has been qualified:

- "TT3" Perfect: when the femoral head was well placed under the roof with normal spacing.

- "TT2" Good: when there was a tilting of the roof but without loss of parallelism of the spacing.

- "TT1" Passable: when there was a loss of parallelism between the lines without loss of total contact between the head and the roof.

- "TT0" Bad: when there was a loss of contact between the roof and the femoral head.

The congruence head/acetabulum was qualified:

- "TC3" Perfect: when independently of displacement, there is a parallelism between the femoral head and the roof of the acetabulum.

- "TC2" Good: when one of the elements of the remaining acetabulum was no longer cast on the femoral head.

- "TC1" Fair: when the femoral head was initially in a very oval acetabulum.

- "TC0" Bad: when there was no longer any relationship between the head and the acetabulum.

\subsection{Epidemiogical Aspects}

A total of 63 exploitable records of patients with traumatic acetabulum injuries (TAI) have been identified in 5 years. The annual frequency was 12.6 patients. TAI accounted for $0.8 \%$ of the reasons for consultations. Forty patients (63.5\%) consulted for coxofemoral dislocations associated or not with an acetabulum fractures. Forty-one patients (65.1\%) consulted for a fractures of the acetabulum associated with or not to coxo-femoral dislocations, ie an annual frequency of 8 patients. More than half of the patients (54\%) were transported by the National Fire Brigade. Patients referred (32\%), direct admissions (13\%) and patients transferred from another department (1\%) constituted the other modes of admission to traumatic emergencies.

They came mainly from the city of Ouagadougou (68.2\%), or from localities 100 kilometers $(8 \%)$ or more than 100 kilometers $(23.8 \%)$. The mean age of patients with hip dislocations was 34.2 years (range 17 - 73) and 36.3 years (range 16 - 65) in acetabulum fractures.

Forty-five men (71.4\%) and 18 women (28.6\%) presented TAI, a sex ratio of 2.5. Thirty-one men (77.5\%) and nine women (22.5\%) presented coxo-femoral dislocations. Acetabular fractures occurred in 29 men (70.7\%) and 12 women (29.3\%). All our patients were autonomous; no medical pathology was found in 56 patients $(88.9 \%)$. In contrast, 7 patients presented with hypertension (4 cases), diabetes, asthma and schizophrenia (1 case each). Road traffic accidents 
(RTAs) were the predominant etiology (97.5\%) in coxo-femoral dislocations, including one case of stroke and voluntary injury (2.5\%). In acetabular fractures, RTAs were the predominant cause $(87.8 \%)$, followed by falls averaging 3.8 meters $(9.8 \%)$. Table 2 shows the distribution of patients according to the type of collision and the type of injury. Injuries involving a car and a motorcycle were the most common (34.9\%). The traumatic mechanism was most often direct $(73 \%)$. In the indirect mechanism (27\%), the point of impact was mainly the anterior flexion of the knee (dashboard), (17.5\%).

\subsection{Anatomical and Clinical Characteristics}

The average consultation time was 11.6 hours $(1-96)$. Forty patients $(63.5 \%)$ consulted within the first 6 hours, 16 patients (25.4\%) between 6 and 24 hours and 7 patients (11.1\%) after 24 hours. Left TAI predominated (54\%). Bilateral forms were observed only in acetabular fractures (9.7\%). The left hip dislocations predominated (52.5\%) followed by those of the right hip (47.5\%). Left acetabular fractures predominated $(48.8 \%)$, followed by straight $(41.5 \%)$ and bilateral forms (9.7\%). Pain and functional impotence of the pelvic limb (PL) were noted in all patients. Hemodynamic status was poor in 13 patients $(20.6 \%)$ and good in 50 others (79.4\%).

The vicious attitude of the injured Pelvic limb (PL) existed in 41 patients (65.1\%). The shortening of the injured Pelvic limb (PL) was noted in 37 patients (90.2\%); PL was long in 4 other patients $(9.8 \%)$.

Table 2. Distribution of patients by type of collision.

\begin{tabular}{ccccc}
\hline \multirow{2}{*}{ Type of collision } & \multicolumn{2}{c}{ Coxo-femoral dislocation } & \multicolumn{2}{c}{ Acetabular fracture } \\
\cline { 2 - 5 } & Number & $\%$ & Number & $\%$ \\
\hline Motorcycle only & 3 & 7.7 & 0 & 0 \\
Motorcycle-Animal & 1 & 2.6 & 0 & 0 \\
Motorcycle-Motorcycle & 7 & 17.9 & 5 & 13.9 \\
Motorcycle-Pedestrian & 1 & 2.6 & 0 & 0 \\
Moto-Tricycle & 1 & 2.6 & 1 & 2.8 \\
Single bike & 1 & 2.6 & 1 & 2.8 \\
Bicycle -Tricycle & 1 & 2.6 & 0 & 0 \\
Single car & 7 & 17.9 & 8 & 22.2 \\
Car-Animal & 0 & 0.0 & 1 & 2.8 \\
Motorcycle-car & 10 & 25.6 & 14 & 38.9 \\
Car-pedestrian & 2 & 5.1 & 2 & 5.6 \\
Tricycle-car & 1 & 2.6 & 1 & 2.8 \\
Car-bike & 1 & 2.6 & 0 & 0 \\
Car-Car & 3 & 7.7 & 3 & 8.3 \\
Total & 39 & 100 & 36 & 100 \\
\hline & & & & \\
\hline
\end{tabular}


Conventional radiography in incidence (face, profile and three quarters wing and obturator) was prescribed to confirm the diagnosis of the varieties of hip dislocations, but also for the diagnosis of fractures of the acetabulum. Computed tomography (CT) was performed in 16 patients $(25.4 \%)$ and the lesions were clarified in 2 cases of pure irreducible coxofemoral dislocations and in 14 cases of acetabulum fractures. Four patients had a CT scan for severe CT and 1 patient a thoracic CT scan for thoracic trauma with ribs.

According to Bigelow's classification, we counted 7 irregular dislocations (17.5\%), including 2 subcotyloid and 5 sus-cotyloid. Thirty-three regular dislocations $(82.5 \%)$ were distinguished in 28 posterior dislocations (iliac or ischiatic) (Figure 1) and 5 anterior dislocations (obturator or pubic) (Figure 2).

According to Levin's classification, type I dislocations predominated (47.5\%) (Table 3).

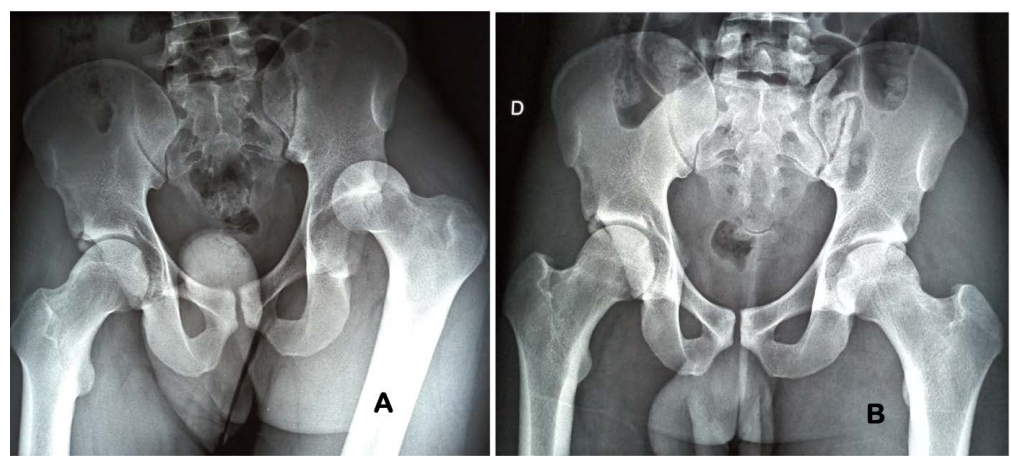

Figure 1. 22-year-old patient, footballer; passenger on a tricycle, who, following a collision with a car, presented: (A) A left iliac dislocation on the incidence of the front pelvis; it was treated by Boëhler's orthopedic method, followed by glued traction. He was not seen again after he left the service; (B) Post-reduction picture of the front pelvis.

Table 3. Distribution of dislocations according to Levin's classification $(n=40)$ and elementary fractures of acetabulum according to Judet and Létournel $(\mathrm{n}=22)$.

\begin{tabular}{|c|c|c|c|c|c|}
\hline \multicolumn{3}{|c|}{$\begin{array}{c}\text { Levin classification of } \\
\text { coxo-femoral dislocations }\end{array}$} & \multicolumn{3}{|c|}{$\begin{array}{l}\text { Judet and Letournel classification of } \\
\text { elemental fractures of acetabulum }\end{array}$} \\
\hline $\begin{array}{c}\text { Type of coxo-femoral } \\
\text { dislocations }\end{array}$ & Number & $\%$ & $\begin{array}{l}\text { Type of elementary } \\
\text { acetabular fracture }\end{array}$ & Number & $\%$ \\
\hline $\begin{array}{l}\text { Type I: pure dislocation } \\
\text { without instability with } \\
\text { concentric reduction }\end{array}$ & 19 & 47.5 & Posterior wall & 11 & 50 \\
\hline $\begin{array}{l}\text { Type II: irreducible } \\
\text { dislocation without fracture } \\
\text { of the head or acetabulum }\end{array}$ & 2 & 5 & Posterior column & 6 & 27.3 \\
\hline $\begin{array}{l}\text { Type III: unstable hip after } \\
\text { reduction or incarceration. }\end{array}$ & 1 & 2.5 & Anterior wall & 1 & 4.5 \\
\hline $\begin{array}{l}\text { Type IV: association with a } \\
\text { fracture of the acetabulum }\end{array}$ & 18 & 45 & Anterior column & 4 & 18.2 \\
\hline $\begin{array}{l}\text { Type V: association with } \\
\text { fracture of the head or neck }\end{array}$ & 0 & 0 & - & - & - \\
\hline Total & 40 & 100 & Total & 22 & 100 \\
\hline
\end{tabular}




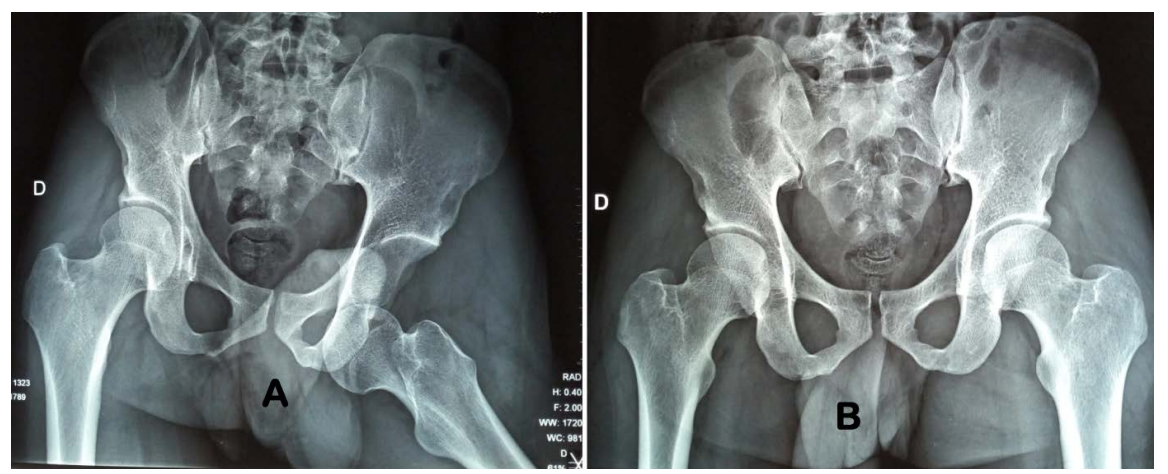

Figure 2. 38-year-old mechanic, motorcyclist patient who, following a collision with another motorcyclist, presented: (A) A left obturator dislocation on the initial image of the front pelvis. He was treated by Boëhler's orthopedic method. This patient was not seen again after his discharge from hospital; (B) Post-reductional image in incidence of the front pelvis.

According to Judet and Letournel's classification, acetabular fractures were distinguished into 22 elementary fractures (34.9\%) and 23 complex fractures (36.5\%). The posterior elementary fractures were divided into 11 posterior wall fractures (Figure 3 and Table 3) and 6 posterior column fractures; the anterior elementary fractures were divided into 4 anterior column fractures and one anterior wall fracture.

Table 4 illustrates the distribution of complex acetabular fractures (Figure 4).

Our patient was released against medical advice (lack of financial means for surgical reduction) after 38 days of glued traction. We counted 22 pure hip-femoral dislocations; an association with acetabulum fractures was noted in 18 cases. Associated lesions are shown in Table 5.

Serious and life-threatening lesions caused a general poor state of health with shock in 13 patients and poly-trauma in 7 patients. These lesions are illustrated in Table 6. Immediate complications were dominated by 13 states of shock, vascular lesion, 25 cutaneous openings. No cutaneous opening was directly related to TAI. Two irreducible coxo-femoral dislocations constituted the early complications by musculo-ligamentary interposition.

\section{Results}

\subsection{Therapeutic Aspects}

The average time to manage TAI was 15.9 hours $(2-100)$. Patients with coxofemoral dislocation were treated within an average of 17 hours $(2-74)$. The average time to treat victims of acetabular fractures was 20 hours $(2-100)$.

Table 7 gives the distribution of patients according to the time of care and to the type of lesion.

The restoration of hemodynamic status was performed in all our patients. Thromboembolic prevention with low molecular weight heparins (LMWH) was performed in all patients. Antibiotics were prescribed in 25 patients with soiled wounds. Six anemic patients (mean hemoglobin level of $5.2 \mathrm{~g} / \mathrm{dl}(3.2-8.6 \mathrm{~g} / \mathrm{dl})$ 
Table 4. Distribution of complex fractures according to Judet and Létournel $(n=23)$.

\begin{tabular}{ccc}
\hline Localization & Number & $\%$ \\
\hline Transversal & 6 & 26.1 \\
Posterior column + posterior wall & 4 & 17.4 \\
Transverse + rear wall & 4 & 17.4 \\
Anterior column + Hemi-transposterior fracture & 4 & 17.4 \\
Two columns & 5 & 21.7 \\
Total & 23 & 100 \\
\hline
\end{tabular}

Table 5. Distribution of lesions associated with coxo-Femoral dislocations and acetabular fractures.

\begin{tabular}{|c|c|c|c|c|}
\hline \multirow{2}{*}{ Associated lesions } & \multicolumn{2}{|c|}{ Coxofemoral dislocations } & \multicolumn{2}{|c|}{ Acetabular fractures } \\
\hline & Number & $\%$ & Number & $\%$ \\
\hline Fracture-embarrassment of the skull & - & - & 1 & 2.1 \\
\hline Facial smash & 1 & 2.7 & 1 & 2.1 \\
\hline Fractures of the dental arch & - & - & 1 & 2.1 \\
\hline Lumbar spine fracture & 1 & 2.7 & 1 & 2.1 \\
\hline Coast fracture & 1 & 2.7 & 2 & 4.2 \\
\hline Fractures of acetabulum & 18 & 48.6 & - & - \\
\hline Fractures of the shutter frame & 4 & 10.8 & 6 & 12.5 \\
\hline Coxo-femoral dislocations & - & - & 18 & 37.5 \\
\hline Femur fractures & 3 & 8.1 & 5 & 10.4 \\
\hline Tibia fracture & 1 & 2.7 & 1 & 2.1 \\
\hline Fracture of the collarbone & 1 & 2.7 & 1 & 2.1 \\
\hline Fracture of the humerus & 1 & 2.7 & & \\
\hline Fractures of the radius & 3 & 8.1 & 5 & 10.4 \\
\hline Fracture of the ulna & 1 & 2.7 & - & \\
\hline Wrist fracture & - & - & 1 & 2.1 \\
\hline Fractures of the bones of the hand & 2 & 5.4 & - & - \\
\hline Total & 37 & 100 & 48 & 100 \\
\hline
\end{tabular}

Table 6. Distribution of serious lesions associated with ATI.

\begin{tabular}{ccc}
\hline \multirow{2}{*}{ Serious injuries } & Coxo-femoral dislocation & Fracture of acetabulum \\
\cline { 2 - 3 } & Number & Number \\
\hline Extradural hematoma & 2 & 1 \\
Concussion & 2 & 2 \\
haemoperitoneum & 1 & 1 \\
Bladder and urethral contusion & 1 & 1 \\
Lesion of the popliteal artery & 1 & 1 \\
Total & 7 & 6 \\
\hline
\end{tabular}




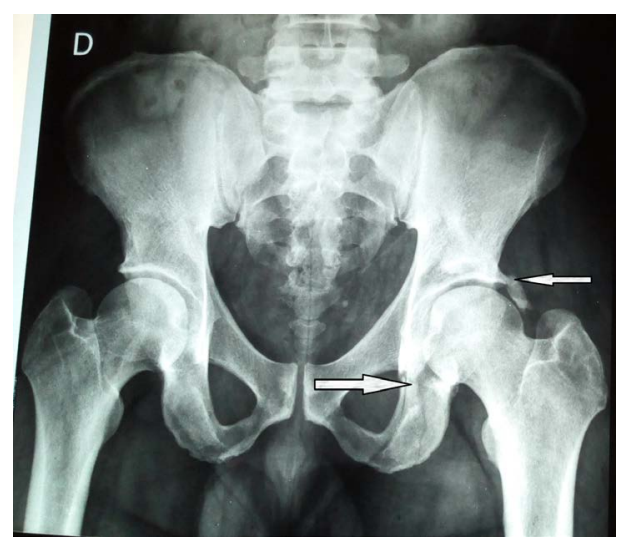

Figure 3. A 31-year-old commercial patient, who had been the victim of a RTA involving a car and a motorcycle, had a fracture of the posterior wall of the acetabulum and ischium (see arrows). This patient received orthopedic treatment by traction glued to the bed. He was not seen again after he left the service.

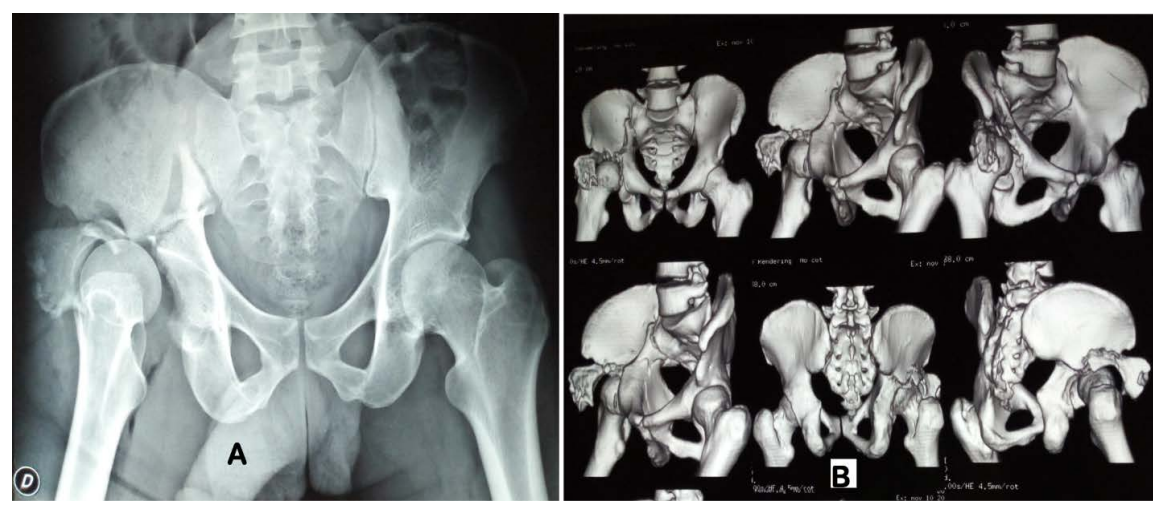

Figure 4. 33-year-old patient, apprentice driver, motorcyclist, who, following a collision with a car, presented: (A) front pelvis image showing a complex fracture of the right acetabulum (fracture of the posterior wall, posterior column and anterior wall); (B) Plate with scan reconstruction to better visualize bone lesions.

Table 7. Distribution of patients according to the time of care.

\begin{tabular}{ccccc}
\hline \multirow{2}{*}{ Delay before treatment } & \multicolumn{2}{c}{ Coxo-femoral dislocations } & \multicolumn{2}{c}{ Fractures of acetabulum } \\
\cline { 2 - 5 } & Number & $\%$ & Number & $\%$ \\
\hline$<6$ hours & 18 & 45 & 19 & 42.2 \\
$\geq 6$ hours $\leq 24$ hours & 18 & 45 & 20 & 44.5 \\
$>24$ hours & 4 & 10 & 6 & 13.3 \\
Total & 40 & 100 & 45 & 100 \\
\hline
\end{tabular}

were transfused. Orthopedic reduction under general anesthesia was used in 38 patients, 21 of whom had pure coxofemoral dislocation. The average reduction time was 17.5 hours $(4-102)$. For the 18 coxofemoral fracture-luxations, the glued traction was achieved after reduction of dislocation. The average duration of traction was 26.2 days $(1-48)$ in case of pure dislocations. Tensile strength adhered to the bed plane was indicated in 37 acetabular fractures. The 
average duration of this traction was 6 weeks (6 - 8 weeks) in coxofemoral fracture-luxation and/or acetabular fractures. The average operating time was 14 hours (12 - 16). The Kocher-Langenbeck approach was used for surgical reduction. Surgical reduction was performed in two patients with irreducible pure coxofemoral dislocation. Seven acetabular fractures were treated surgically. The average time to osteosynthesis was 33.8 days (12 hours - 90 days). Four osteosynthesis were performed per screwed plate and three by simple screwing (Figure 5).

Table 8 provides summary of 7 patients treated by surgical method.

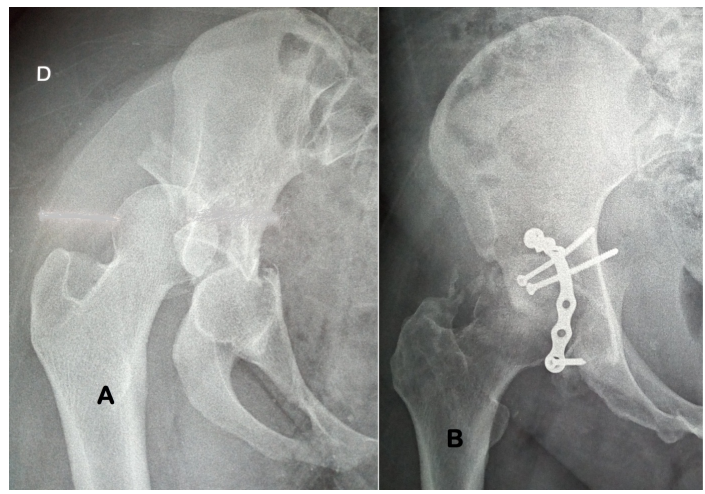

Figure 5. 43-year-old patient, teacher, following a car crash against a tree, presented: A-a transverse juxta-articular and posterior wall fracture of the acetabulum; associated with iliac dislocation on the initial image of the right hip from the front; B-postoperative image in incidence $3 / 4$ wing of a screwed plate osteosynthesis after orthopedic reduction of dislocation by the Boëhler method. The functional result was considered good.

Table 8. Summary of the seven osteosynthesis for acetabular fractures.

\begin{tabular}{|c|c|c|c|c|c|c|}
\hline Case & Sex & Age & Occupation & $\begin{array}{l}\text { Type of } \\
\text { Fracture }\end{array}$ & $\begin{array}{c}\text { Therapeutic } \\
\text { method }\end{array}$ & $\begin{array}{l}\text { Functional } \\
\text { results }\end{array}$ \\
\hline 1 & $\mathrm{M}$ & 43 & Teacher & $\begin{array}{l}\text { Transverse fracture } \\
+ \text { posterior wall }\end{array}$ & $\begin{array}{l}\text { Osteosynthesis with } \\
\text { Shermann plate }\end{array}$ & Good \\
\hline 2 & M & 56 & Trader & Transverse fracture & Screw plate & Good \\
\hline 3 & M & 30 & Logistician & $\begin{array}{l}\text { Fracture of the } \\
\text { posterior wall and } \\
\text { roof of the acetabulum }\end{array}$ & $\begin{array}{l}\text { Osteosynthesis } \\
\text { with plate }\end{array}$ & Good \\
\hline 4 & M & 37 & $\begin{array}{l}\text { Education } \\
\text { Counsellor }\end{array}$ & $\begin{array}{l}\text { Transverse Fracture } \\
\text { + Posterior Wall }\end{array}$ & $\begin{array}{c}\text { Screw } \\
\text { Osteosynthesis }\end{array}$ & Very Good \\
\hline 5 & M & 31 & Constable & $\begin{array}{l}\text { Fracture of the } \\
\text { posterior wall }\end{array}$ & $\begin{array}{l}\text { Osteosynthesis with } \\
\text { flexible screwing }\end{array}$ & Good \\
\hline 6 & $\mathrm{~F}$ & 45 & $\begin{array}{l}\text { Administrative } \\
\text { Secretary }\end{array}$ & $\begin{array}{l}\text { Fracture of the } \\
\text { posterior column }\end{array}$ & $\begin{array}{l}\text { Osteosynthesis } \\
\text { with screw }\end{array}$ & Good \\
\hline 7 & M & 17 & Student & T-Fracture & $\begin{array}{c}\text { T-Plate } \\
\text { Osteosynthesis }\end{array}$ & $\begin{array}{l}\text { Osteonecrosis } \\
\text { of the } \\
\text { femoral head }\end{array}$ \\
\hline
\end{tabular}


The post-reduction clinical assessment carried out in the event of coxofemoral dislocation associated or not with acetabular fractures had found a stable hip in 32 cases, long iso pelvic limbs in 38 cases, complete hip mobility found in 35 cases and no piston in 37 cases. Post-reduction medical imaging confirmed 36 concentric reductions (90\%) in coxofemoral dislocations. The associated cutaneous openings were treated within an average of 5 hours (3 - 12 hours). Fractures associated with TAI were treated within an average of 12.7 hours ( 2 - 73 days).

\subsection{Evolutionary Aspects}

Two cases of death were reported (3.2\%), one in a hemorrhagic shock table and the other in a septic shock table. Post-treatment complications included 13 pressure ulcers, 1 bronchopneumonia, 5 hypertensive attacks, 1 urinary tract infection, 1 secondary pubic dislocation after orthopedic reduction of acetabular fracture, 1 iatrogenic lesion of the ischial nerve, 1 peroperative hemorrhage, 1 surgical site infection, 1 periarticular ossification, 3 necrosis of the femoral head and 3 hip osteoarthritis. The average duration of hospitalization was 26.7 days ( 1 - 63). A post-therapeutic improvement was observed in 31 victims of hip dislocations $(77.5 \%)$ and 31 fractures of the acetabulum (75.6\%). Only 7 patients $(11.1 \%)$ were reviewed and evaluated. Only one patient had consolidated his fracture at 7 months. The reduction was good in one patient at 6 months of follow-up, but he suffered from persistent pain in the hip. As for the quality of life, one patient had total autonomy, five patients had partial autonomy and one patient was not autonomous. According to Merle d'Aubigné, Matta and Duquennoy et al. [9] [10], the reduction was anatomical in 1 case, satisfactory in 5 cases, unsatisfactory in 1 case, with satisfactory head-to-head congruence; the functional results were very good ( 1 case), good (5 cases) and bad ( 1 case). The evolutionary results are specified in Table 9.

\section{Discussion}

Despite some limitations and constraints, our five-year retrospective study of recent acetabular trauma allows us to make some comments. The mean age of 34.2 years of patients with hip dislocation and 36.3 years of acetabulum fractures in our series, is in the age range indicated by Rabah et al. [11] (31 - 35). The male predominance of TAIs can be explained by the fact that the male population appears to be the most active, the most mobile, the most reckless and also the most vulnerable in traffic accidents. This fact is corroborated by the report of the Ouagadougou municipal police on road accidents in the capital in 2013, which indicates that $68.4 \%$ of accident victims were men [9]. Left hip dislocations accounted for $(52.5 \%)$, left acetabulum fractures (48.8\%) predominated with 4 bilateral forms (9.8\%). Seven irregular dislocations were noted. Of the 33 regular dislocations, the posterior variety was the most common $(51.5 \%)$ followed by pubic varieties $(15.2 \%)$. The predominance of iliac or posterior hip dislocation, may be explained by the mechanism of injury, physiology, and anatomical structure of the posterior hip area. According to the Letournel and Judet 
Table 9. Results of the seven patients reviewed and evaluated.

\begin{tabular}{|c|c|}
\hline \multicolumn{2}{|c|}{ Functional results according to the criteria of Postel Merle d'Aubigné [10] } \\
\hline Résultats Results & $\%$ \\
\hline Excellent & 0 \\
\hline Very good & 1 \\
\hline Good & 5 \\
\hline Poor & 0 \\
\hline Bad & 1 \\
\hline \multicolumn{2}{|c|}{ Quality of reduction according to Matta's criteria [10] } \\
\hline Anatomical & 1 \\
\hline Satisfactory & 5 \\
\hline Not satisfying & 1 \\
\hline \multicolumn{2}{|c|}{ Head-to-Roof Congruence (TT) according to the criteria of Duquennoy et al. [10 } \\
\hline TT0 & 0 \\
\hline TT1 & 2 \\
\hline TT2 & 5 \\
\hline TT3 & 0 \\
\hline \multicolumn{2}{|c|}{ Head-Cotyle Congruence (TC) according to the criteria of Duquennoy et al. [10] } \\
\hline TC0 & 0 \\
\hline TC1 & 3 \\
\hline TC2 & 4 \\
\hline TC3 & 0 \\
\hline
\end{tabular}

classification, elementary acetabular fractures were the most common (57.8\%). Fractures of the posterior wall predominated (26.8\%). Because of the velocity and violence of the trauma, TAIs occur in a context of poly trauma. The seat and the severity of the associated lesions vary. All parts of the body are prone to injury. This is the finding already made by Chagou et al. [12], who noted $45 \%$ associated lesions, $20 \%$ of which were serious lesions, mainly cranioencephalic (10\%) and thoracic (10\%) trauma. Standard radiography is the main method of diagnosing acetabulum trauma. As pointed out by Burdin et al. [13], the threequarter wing and obturator incidences of the acetabulum make it possible to confirm the types of lesions. The mean duration of management was 15.9 hours (2 - 100) in our study. Orthopedic reduction by the Boëhler method was performed in $95 \%$ of hip dislocations. Surgical reduction by the Kocher-Langenbeck approach was performed in two cases of irreducible coxofemoral dislocations (5\%). Pietu [1] reports that $96.67 \%$ of patients received orthopedic treatment compared to $3.33 \%$ for blood reduction. The average orthopedic reduction time was 17.5 hours $(4-102)$ while the blood reduction time was 14 hours (12 16). These reduction times are longer than those recommended by Pietu [1] who specified that the ideal time should not exceed 6 hours and if possible be less 
than 24 hours. The predominance of orthopedic reduction may be explained by the fact that this method is inexpensive, easier to perform and does not require a particular strategy or longer experience. The insufficiency of our technical platform and the absence of a qualified surgeon for the acetabulum surgery, reinforce the choice of the orthopedic method. The reduction period is a crucial element in the evolution and prognosis of coxo-femoral dislocations. The long reduction period of our series (11.6 hours) can be explained by the long consultation time (on average 11.6 hours). Orthopedic reduction by acetabular fracture bed traction was the most common in our series $(82.2 \%)$. On the other hand, Meyer et al. [2], Chagou et al. [12] performed orthopedic treatment (62.5\%), in trans-tibial or condylar traction for 15 to 45 days. Our insalubrious hospital environment obliges us to prefer glued traction to transosseous traction which carries an infectious risk. Only 07 acetabular fractures were surgically treated after orthopedic traction. The Kocher-Langenbeck approach was used for the osteosynthesis of acetabular fractures, while Hue et al. [3] recommend the extended ilio-femoral approach, which allows a strictly anatomical surgical reduction of complex acetabular fractures, to "save" the hip. Mean operative time for acetabular fractures was 33.8 days (12 - 90). Like Chagou et al. [12], four screwed plate and three screw fixation osteosyntheses were performed in the acetabular fractures of our series. The insufficient number of orthopedic surgeons, the low socio-economic level of the patients, the high cost of the surgical interventions, the under-equipment of our technical platform, the long delay of care and the non permanent availability of the products of resuscitation (globules red, whole blood and platelet concentrates), explain the predominant choice of the orthopedic method in our series. Like Pietu et al. [1], Burdin et al. [13], Barsotti et al. [14], the post-reduction traction of the coxo-femoral dislocations of our series was performed for 26.2 days $(1-48)$. This traction was followed by a discharge for three weeks, followed by four weeks of loading and functional rehabilitation of the hip. In our series, transosseous traction was not performed due to poor hospital hygiene. The average duration of traction was 25.8 days ( $2-50)$. Nazarien et al. [15], Pietu et al. [1] proposed a functional treatment of 5 to 6 weeks without traction in case of stable fracture, the passive mobilization is possible after one week and increases between 2 and 5 weeks; full support may be allowed between 75 and 90 days. In case of displaced fracture, they recommend transcondylar traction for 45 days with decreasing weight; a loading is then possible after three months. Iatrogenic lesions of the ischial nerve, infection of the operative site, and extensive bleeding were perioperative and postoperative complications. Decubitus complications included 13 pressure ulcers, one urinary tract infection, one bronchopulmonary disease and three hypertensive attacks. A pubic dislocation secondary to a reduction of fracture dislocation of the acetabulum was noted. Late complications included necrosis of the femoral head, periarticular ossification, and three hip osteoarthritis. Osteosynthesis of acetabular fractures yielded 1 very good, 5 good and 1 poor result. Except for the small number of cases observed, our evolutionary results are much weaker than those of the li- 
terature. This low rate could be explained by the fact that a small number of our patients were reviewed as well as the very high number of discharges against medical advice (22\%). The rehabilitation of the degraded and narrow roads, the intensification of the sensitization of the populations on the respect of the elementary rules of the highway code (eviction of the drunk driving, the speeding, the surcharges) can contribute to reduce the frequency of traffic accidents. The training of firefighters on emergency medical procedures in addition to emergency care, a medical transport system for the wounded through the UAS (Universal Hospitality Service), the increase in the number of orthopedic surgeons will allow early and more effective TAI management. The fight against the poverty of the populations, the application of the universal health insurance for all the patients of emergencies, the modernization of our technical platform, the reinforcement of the organization and the coordination of the work (institution of protocols taking into traumatological emergencies, postgraduate teaching on the management of polytrauma and TAI) may facilitate the treatment of these lesions in order to obtain more perforating functional results.

\section{Conclusion}

The profile of the TAI patient is this active young man, aged 25 to 35, who suffered a violent hip injury following a traffic accident. This violence of the shock also explains the lesional association. Radiography of the front pelvis and 3/4 wing and obturator oblique X-rays allow the diagnosis of TAI; CT is sometimes a contributory factor in the lesional balance of acetabulum fractures. The left hip is the most affected. Among the 40 coxofemoral dislocations recorded, the iliac or posterior high variety predominated. Of the 41 acetabular fractures, 4 were bilateral; elementary fractures $(57.8 \%)$, represented mainly by posterior wall fractures (42.3\%), predominated. Treatment of TAI was mainly orthopedic: $95 \%$ of coxofemoral dislocations and $82.2 \%$ of acetabular fractures. Reduction difficulties were found in two cases of obturator dislocation, which led us to perform the surgical reduction. Only 7 acetabular fractures were treated by the surgical method. The non-respect of the follow-up appointments, did not allow us to correctly analyze the evolutionary aspects. Improving the therapeutic management of TAI requires the improvement of our technical platform. To do this, a comprehensive prospective study incorporating all these parameters is essential.

\section{Conflicts of Interest}

The authors declare no conflicts of interest regarding the publication of this paper.

\section{References}

[1] Pietu, G., Malissard, M., Raynaud, G. and Letenneur, J. (1993) Luxation traumatiques pures de hanche. In: Encycl Méd Chir, Traité de l’Appareil locomoteur, Elsevier, Paris, 19 p.

[2] Meyer, A., Biette, G. and Catonne, Y. (2008) Luxation de hanche sans fracture du 
cotyle associée: Méta-analyses et série de cas rapportés. Maîtrise Orthopédique, No. 176.

[3] Hue, A.G., Gauthé, R., Tobenas-Dujardin, A.C., Vallée, A., Mouton, J. and Dujardin, F. (2018) Fractures complexes de l'acétabulum: Faut-il abandonner la voie ilio-fémorale élargie? Résultats à 20 ans de recul. Revue de Chirurgie Orthopédique et Traumatologique, 104, 314-318. https://doi.org/10.1016/j.rcot.2018.03.003

[4] Strauss, C. and Palau, R. (1990) Fracture du bassin. In: Encyclopédie Médico-chirurgicale, Radiologie de l'appareil locomoteur, Editions Scientifiques et Médicales, Elsevier, Paris.

[5] Laude, F., Puget, J. and Martimbeau, C. (1999) Fractures de l'acétabulum. In: Encyclopédie Médico-chirurgicale, Appareil locomoteur, Elsevier, Paris, 17 p.

[6] Jouffroy, P. and Raoult, A. (2002) Techniques chirurgicales dans les fractures du bassin. In: Encycl Méd Chir, Editions Scientifiques et Médicales, Techniques chirurgicales-Orthopédie-Traumatologie, Elsevier, Paris, 44-510.

[7] Miquel, A., Lesavre, A., Rocher, L., Court, C., Martin, L. and Menu, Y. (2005) Diagnostic tomodensitométrique des fractures du bassin: Reconnaître, classer et reconstruire. Service de Radiologie Centrale, Le Kremlin-Bicêtre, France, 42 p.

[8] Mouhsine, E., Garofalo, R., Theumann, N., Borens, O., Chevalley, F. and Wettstein, M. (2008) Traumatismes du bassin. Revue Médicale Suisse, 4, 2723-2730.

[9] OSCO (2014) Rapport 2013 de situation des accidents de la circulation routière dans la commune de Ouagadougou. Ouagadougou. 56 p.

[10] Emma, F., Dambreville, A., Gacon, G. and Kehr, P. (2008) Classifications et scores en chirurgie orthopédique et en traumatologie. Volume 1, 35-50.

[11] Rabah, A., et al. (2014) Fractures de l'acétabulum (paroi postérieure exclue)-aspects anatomo-pathologiques et résultat du traitement. Revue de Chirurgie Orthopédique et Traumatologique, 100, S242-S243. https://doi.org/10.1016/j.rcot.2014.09.079

[12] Chagou, A., Hmouri, I., Rhanim, A., Lahlou, A., Berrada, S.M. and Yaacoubi, M. (2014) Les fractures luxations de l'acétabulum: Prise en charge et pronostic à long terme; Étude rétrospective portant sur 40 cas. The Pan African Medical Journal, 19, 90. https://doi.org/10.11604/pamj.2014.19.90.5101

[13] Burdin, G., Hulet, C., Slimani, S., Coudane, H. and Vielpeau, C. (2004) Luxations pures et fractures de tête fémorale. Rhumatologie Orthopédie, 1, 508-520. https://doi.org/10.1016/j.emcrho.2004.08.002

[14] Barsotti, J., Cancel, J. and Robert, C. (2010) Guide pratique de traumatologie. Sixième Edition, Elsevier Masson, Paris, $314 \mathrm{p}$.

[15] Nazarian, S. and Müller, M. (1998) Voies d'abord de la hanche. In: Encycl Méd Chir, Techniques Chirurgicales Orthopédie-Traum. Elsevier, Paris. 